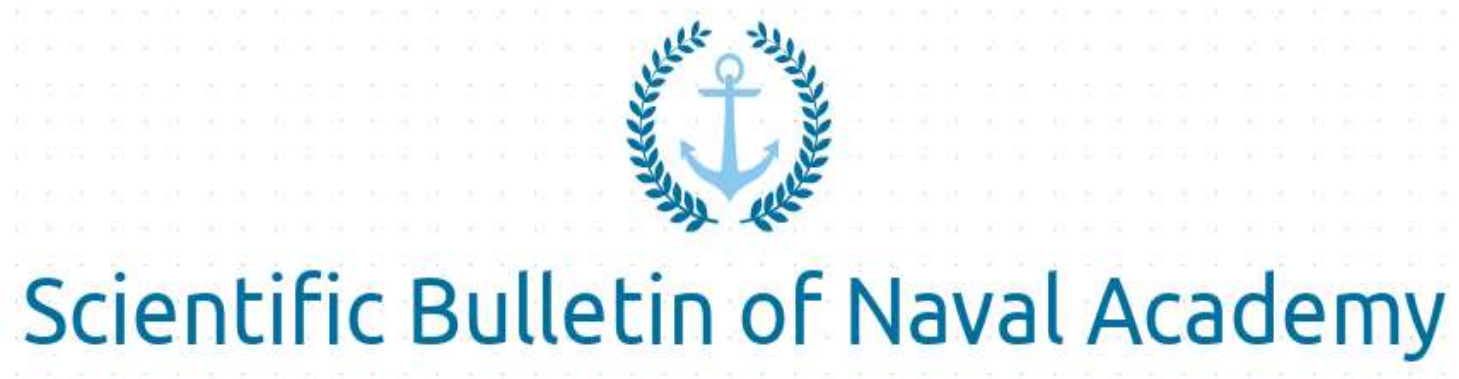

SBNA PAPER • OPEN ACCESS

\title{
Considerations regarding the sources of corruption
}

To cite this article: Violeta Ioana Nagâț, Scientific Bulletin of Naval Academy, Vol. XXIII 2020, pg. 270-277.

Available online at www.anmb.ro

ISSN: 2392-8956; ISSN-L: 1454-864X 


\title{
Considerations regarding the sources of corruption
}

\author{
Violeta Ioana Nagâţ \\ Ph. D Student at the Information Academy "Mihai Viteazul", Bucharest,Romania \\ E-mail: vio_nag@yahoo.com
}

\begin{abstract}
Corruption is a threat to democracy, the rule of law, social equity and justice, erodes the principles of efficient administration, undermines the market economy and endangers the stability of state institutions. Therefore, the fight against this phenomenon must be carried out by the legally authorized authorities, with the support of civil society, without any obstruction, so that no one is perceived as being above the law. In this context, the prevention of acts and facts of corruption, by monitoring conflicts of interests and incompatibilities, as well as by controlling the assets acquired illegally, must be the support of any strategy in this field. Adopting adequate measures to prevent the "corruption" phenomenon requires knowing its real size, its complexity, the trigger mechanisms and the consequences produced.

The complexity and the continued diversification of the forms of manifestation of this phenomenon, together with the tendencies of globalization, require the design and elaboration of appropriate strategies, which scientifically and systematically approach the criminogenic sources and the effects of the crime and offer the effective tools for social prevention and control.

The phenomenon of "corruption" is generated by ideologies, norms, individuals and groups with antisocial behavior, institutions and organizations.

Key words:Corruption, democracy, the rule of law, social equity,justice, measures to prevent the "corruption", diversification of the forms of manifestation, The phenomenon of "corruption, ideologies, norms, individuals and groups with antisocial behaviour, institutions, organizations
\end{abstract}

\section{Introduction}

The phenomenon of "corruption" is generated by ideologies, norms, individuals and groups with antisocial behaviour, institutions and organizations.

According to the linguistic definition, the source is the environment or the place (physical and symbolic) where it is produced, where it can be found or from where something is propagated, the place or origin of a thing, source, origin. ${ }^{1}$ The environment constitutes the set of factors, relationships, conditions, institutions, groups and social ideologies, within and under the influence of which an individual or a micro-group is. According to the incorporated social fields, this can be: the political environment (organizations, parties, groups), the public administration environment (civil and military servants) and the economic environment (public and private economic agents). The phenomenon of "corruption" is generated by ideologies, norms, individuals and groups with antisocial behaviour, institutions and organizations that operate and are under the influence of the environment.

\section{Sources of corruption: ideologies}

Ideologies, as a comprehensive and coherent set of ideas, through which a social group interprets the world in which it lives, provide framework interpretations on the essence of social events, phenomena and processes. Each ideology contains ideas that, in certain contexts, can be the foundation of some antisocial behaviours, but the extreme ideologies - based on which dictatorial forms of centralized government are built - constitute the germinating environment of corruption and generate antisocial facts.

\footnotetext{
${ }^{1}$ DEX, ,, Univers Enciclopedic”Publishing House, Bucharest, 1996, p. 1047.
} 


\subsection{Communism:}

- proclaims class conflict and revolutionary struggle for the conquest of political power ${ }^{2}$; its result must be the victory of the proletariat and the establishment of a socialist society without classes, in which private property is abolished, and the means of production and subsistence belong to the community;

- is concerned with the construction of the "party-state", on the assumption that the stateadministrator is the product of capitalism and social division in antagonistic classes, so an instrument of repression, exploitation and domination of one class (bourgeoisie) over another class (proletariat);

- considers that the party-state has as main mission the administration of production and distribution, which gives it the right not to present itself as a government of some people by other people;

- it is marked by dogmatism, sectarianism and opportunism, which marks the birth of the new type of state, in which the professional bodies are dominated by the authority of the laws imposed by the ruling classes.;

- generates a violent political system, which governs society through coercive instruments (army and police).

\subsection{Fascism:}

- builds a "total state", which accumulates all the resources of power that gives it the ability to arbitrarily dispose of people's lives;

- grants absolute powers to the so-called "charismatic leader" by virtue of the same principle of class struggle;

- establishes the power of the single-party, which controls the economy, establishes a monopoly over the means of communication and defence, imposes a system of political and police terror;

- turns to the dictatorship, by taking over the political power by the groups representing the "big industry";

- it turns the state into a "war machine" against all those whom extremist ideology categorizes as "enemies" - either inside or outside;

- it speculates, in particular, the situations in which the administrative state is marked by an acute "economic crisis" and the reduction of profit for the holders of resources.

\subsection{Liberalism:}

- it defends the rights of the individual and maximizes the freedom of action according to the own interests of individuals and interest groups;

- proclaim individual freedom and unlimited possibility to accumulate resources, even to the detriment of other people;

- maintains the so-called "state-administrator" that dominates the "social" through political formulas generating power relations and conflict situations between the holders of resources and those without resources;

- maintains the so-called "state-administrator" that dominates the "social" through political formulas generating power relations and conflict situations between the holders of resources and those without resources;

- it generates perverse effects, such as social disharmony, and individual freedoms become only the property of those who own the resources.

\subsection{Social democracy:}

- it is individualized as a defender of "political democracy", supplemented with "social democracy", necessary to protect "society" from "economic crises" and "political crises", but also to prevent the risk of a "Leninist" revolution

- it conceives the governance only through the state built within the liberal ideological boundaries, by which it assumes the mission of becoming the manager of a "new social order";

\section{${ }^{2}$ Ibidem, p. 85.}


- it rejects economic liberalism and admits the infiltration of socialism in the state, and the expected structural reforms cause perverse social effects;

- builds a type of state faced with two contradictory tendencies: "political violence" (revolution) and parliamentary (tendency to talk a lot and to do less).

\subsection{Christian democracy:}

- is involved by political action in the "reform" of the administrative state, from the need to ensure "public morality", but also to admit a "balance" game between the individual and "society";

- obliges the "liberal type" administrative state to adapt its "speech" to the values inherited from Christianity and to accept the compromise between the church and the state;

- the Catholic variant, as a rule, rejects the idea of "tolerance" and builds a layer in which the "lay" administrators are constantly forced to repeat "à la Canossa" or to accept a de facto or legal alliance between the "spiritual power" of the ecclesiastical pyramid. and the "temporal power" of the state;

- the other catholicizing tendency conceives of a "pluralistic" form of organization emanating from the "masses" and which must be guaranteed consensually and morally against industry, businessmen, the "political class" or even the state.

\subsection{Anarchism:}

- affirms the establishment of a society in which all restraints on the individual are forbidden;

- considers that any form of government, whether or not sanctioned by universal suffrage, is tyranny;

- it generates a new form of society, in which private property is to be abolished, and instead of the national state, "anarchist communities" are created in which power is "delegated and perpetually revocable";

- calls on its partisans to disobey any form of state and to refuse the participation of citizens in public life;

- argues that the central issue of any social organization is that of the individual freedoms of human.

\section{Norms with doctrinal / ideological basis}

The norm, defined as a rule, mandatory provision, fixed by law or by use, but also as an order recognized as obligatory or advisable, imposes rules and models that determine what behaviour is appropriate or not in a given situation, according to the standards required by culture and social order ${ }^{3}$.

In any social - political system the legal normsare defining - in basis of which the general and impersonal rules of conduct are elaborated by the competent state bodies, aspect which acts in a mandatory way for people, as their „citizen” status, but also moral norms(or ethical) - which expresses the rules regarding the behaviour of man in society, its obligations to other people and to society

In particular, the violent political elites, who manage the nation through power relations, elaborate and impose norms from the perspective of their own interest, ignoring the social needs. Even in the "modern democracies" self-defined social organizations, the administrative apparatus is run by a small number of officials, and the elective and governmental functions are monopolized by political professionals. The norms thus constructed create and recreate the type of society in which citizens and their organizations do not hold political power

Usually, violent or inefficient political elites get involved in the administration, through state institutions. They want to maintain their exceptional place within the state apparatus by limiting the number of personnel, but also by maintaining or imposing their members in the strategic points of the administration: the directions of the main central administrations, discretionary functions, chairmen of the commissions of expertise, the control of a certain activity of the state. Their members detach

\footnotetext{
${ }^{3}$ Aurel V. David, The sociology of nations, ,, Dacoromâna” Publishing House, Bucharest, 2005, p. 150 .
} 
themselves from the rest of the senior administration, belonging, in fact, to the central decision-making environment. From this position, it uses, according to interest, the full range of possibilities characteristic of the environment from which they come, such as forms of direct political action, political corruption, political diversion, political destabilization, the exercise of social control by negative means (prohibitions, acts of authority), in the place of positive ones (social orders, suggestions), formal (laws, prescriptions), informal (approvals or disapprovals), explanatory (propaganda) or implicit (example)

Violent political elites create pressure groups that intervene in the political sphere. They do not have the purpose of conquering and exercising power, but they press the political power or the groups competing for power to influence their decisions. Political violence is a refusal of political norms, a deviation from them. Once in power, they use political power to influence through coercion or restraint. They assume the role and regulation of social relations, but they put a restraint on the individual and centralize the political decision, being the enemy of the so-called "civil society".

The legal norms together with the legal relations generated on their basis make up the legal order, a component of the social order, which constitutes the basic condition of the balance of the society order, the guarantee of the realization of the essential rights of the individual and the correct functioning of the institutions. In order to function, any norm (general or particular, prescriptive or proscriptive) must be understood by people, institutions and organizations, in order to comply with it. In the content of any legal norm is stored a certain conscious representation of the legislator in relation to the possible or due conduct of the subjects participating in social relations ${ }^{4}$.

The legal norm has a general character, impersonal and typical, implies an intersubjective report and is obligatory. It is desirable for social norms to work in all areas of social life. In the social environment, they are individualized in the form of professional, technical, political, economic, scientific norms. The viability of the norms is given by the ability of the information processors to construct real norms to tend towards the realization of the ideal norms that associate restrictions, sanctions or repressions of the behaviour considered undesirable.

\section{Individuals with antisocial behaviour}

Antisocial behaviour is that behaviour that deviates from the rules of good coexistence in society, which is a danger to society, being characterized by the following features:

- aggressiveness - which expresses the ability to be aggressive (to attack, to seek cause for dispute, to provoke), as well as behaviours charged with brutal reactions; in psychosociology, the term is equivalent to that of "aggressive behaviour" and most often refers to interpersonal relationships; some researchers believe that the distinctive defining note of aggressive behaviour is intentionality ${ }^{5}$;

- egocentrism - defines a feature of intuitive thinking, materialized by a disposition of spirit or attitude of the individual who relates everything to himself and judges everything from the perspective of personal interests and feelings ${ }^{6}$;

- psychic lability - expresses the disturbance of the affectivity and the capacity of correct or faithful reflection of the reality, which determines the unreliable, changing, unstable character of an individual and has as a consequence the rapid and radical change of the good $\operatorname{mood}^{7}$;

- affective indifference - the affective disorder of an individual, expressed through lack of interest, carelessness, impassibility, insensitivity, coldness towards someone or something.

\footnotetext{
${ }^{4}$ Nicolae Popa, General Theory of Law, „Actami” Publishing House, Bucharest, 1996, p. 159.

${ }^{5}$ Encyclopedia of psychosociology, coordinators Septimiu Chelcea şi Petre Iluţ, EdituraEconomicăPublishing House, Bucharest, 2003, p. 25.

${ }^{6}$ Dictionary of psychology, coordinator Ursula Şchiopu, ,, Babel” Publishing House, Bucharest, 1997, p. 259.

${ }_{7}^{7}$ Paul Popescu Neveanu, Dictionary of psychology, „Albatros” Publishing House, Bucharest, 1978, p. 404.
} 
Thus, the individual with antisocial behaviour is the aggressive (acts or intentionally, provocatively or brutally), egocentric (reports everything to himself and judges everything from the perspective of personal interests and feelings) or psychic lability (incorrectly or unbelievably reflects reality, has character unreliable, changeable, unstable) or manifesting affective indifference (through lack of interest, carelessness, impassibility, insensitivity, coldness towards someone or something)

The case study attests that the environments and places most vulnerable to such behaviour are public institutions in which the law is not respected regarding the hiring and promotion of personnel, tenders and public procurement contracts, financial control, institutionalized and normed relations of service. Also, people prone to traits characteristic of antisocial behaviour are usually involved in acts and facts of corruption, either individually or in association with other individuals

\section{Groups with antisocial behaviour}

Semantically, the group is defined as "a group of people reunited, in a stable or temporary way, based on a community of interests, conceptions, etc." or "that they perform a common action"8. From the perspective of national security, values, interests and security needs, the social group, made up of individuals based on criteria of formal and informal belonging, share a feeling of unity and are linked by relatively stable interaction patterns ${ }^{9}$.

Within the groups, a special place is occupied by the interest group, made up of a variable number of people, who, besides legal economic activities, seek to obtain great illicit gains or other advantages. It exercises influence on the decision-making processes of certain state authorities, public institutions, persons holding public functions, using corruption and illegal actions, usually economicfinancial, to support and realize their interests.

In the democratic society, often the associations of citizens are known as "interest groups", a label that can be synonymous with the terms "pressure group", "lobby", "party", "action committee", politics" or "social movement". The interest groups constitute the group of individuals who, by virtue of common interests (moral, material, professional) are organized to a certain degree, with the purpose of representing, defending and promoting these interests in political, economic, social and cultural life ${ }^{10}$. At the same time, they are voluntary associations that have specific goals precisely defined, they can be moderate or radical, local or international and can represent a segment of the public (pensioners, students, military) or a value (anti-abortion, anti-globalization), in which case they slip towards moral or ideological campaigns.

Sometimes, the activity of the interest groups or the pressure groups is related to the lobby, activity carried out by the agents (technical or lucrative organizations), in order to influence the legislative power or the administrative actions ${ }^{11}$. They hire the services of interest groups or pressure groups. In essence, the lobby is a specific means, outside the usual constitutional mechanisms, which facilitates the imposition of privileged interests, as a group, in the decision-making process.

The 1946 US federal law requires lobby groups to indicate their financial means and declare the list of accredited members to be admitted to the congressional corridor. The representatives of the different lobbies testify before the committees of the parliament and bring to their notice important facts for the legislature, which serve particular interests. Except in cases of bribery and criminal offense, the US government does not restrict their activity, but draws attention to the possible negative effects of the undertaken actions and operations undertaken.

If the actions of the interest groups or the pressure groups violate the legal provisions and carry out illicit activities, they become organized criminal groups ${ }^{12}$. These are structured groups, consisting of

\section{${ }^{8}$ DEX, ,, Univers Enciclopedic” Publishing House, Bucharest, 1996, p. 437.}

${ }^{9}$ Dictionary of Sociology, ,, Univers Enciclopedic” Publishing House, Bucharest, 2003, p. 265.

${ }^{10}$ Sergiu Tămaş, Political Dictionary. Institutions of democracy and civic culture, ,Academiei Române” Publishing House, Bucharest, 1993, p. 120.

${ }^{11}$ Dictionary of sociology,,, Univers enciclopedic” Publishing House, Bucharest, 2003, p. 155.

${ }^{12}$ The group formed occasionally for the purpose of immediately committing one or more offenses does not constitute an organized criminal group, which has no continuity or a determined structure or predetermined roles for its members within the group.- Penal Code adopted in 2009 (Law 286/2009) and entered into force on February 1, 2014. It contains 446 articles, divided into two parts: General Part Articles (1-187) and Special Part Articles (188-446). 
three or more persons, which exist for a period of time and act in a coordinated manner with a view to committing one or more serious offenses, to obtain, directly or indirectly, a financial benefit or other material benefit.

Such groups, whose actions are confined to the organized economic-financial crime, are made up of persons who, besides legal economic activities, seek to obtain illicit gains or other benefits, by initiating and carrying out illegal actions, usually economic-financial, which generates damage to the public or private assets, as well as destabilizing effects in the economic-social plane, which can affect national values, interests and security needs. They are not based on ideological considerations, pursuing, almost without exception, the realization of material or financial advantages.

These groups have the following characteristics:

- represents a self-regulatory system, capable of being organized autonomously, according to the internal rules that ensure the coordination of the actions and the cooperation between the component members;

- in general, I suppose direct relationships, of the "face to face" type, especially regarding the actions of the leader, who has a relatively consolidated position;

- they are, usually, stable, due to the interdependence and consensus of the members, interested in adopting a common attitude and regarding the ways to achieve the objective, by circumventing or violating the legal norms;

- manifests the tendency to co-opt new persons who, through their position, allow access to resources, confer "security", extension of activities and protection of illicit actions.

The membership of individuals in a particular group does not exclude the possibility that they participate in the actions of other groups, depending on personal interests and options, climate and interaction with other members of the groups.

The motivation of associating some people in such groups is usually the interest in obtaining an advantage or material or financial use. On a personal level, joining a certain group of interests that carry out illicit actions can be motivated by various means: from enrichment, to obtaining a privileged position in the society and professional promotion, to the disruption of actions taken by opponents or competitors. The members of the group are, at any time, available to act in order to fulfil the tasks outlined by the leader.

Such groups, which act legally in the area of the underground economy, are different from the Mafia-type organizations, which have a consolidated organization, have a charismatic leader and wellestablished hierarchies and seek to obtain profits from various illegal activities, specific to crossborder organized crime., respectively prostitution, human trafficking, drugs, weapons, ammunition and military equipment, placing of false payment means, illegal gambling, borrowing with cash, extortion of funds, etc. These are made up exclusively or predominantly of foreign citizens, while the interest groups that carry out illegal activities have, as a rule, a predominantly national character, being made up of naturalized Romanians and foreigners, who act in the economic sphere, but which can be transformed. in mafia-like structures ${ }^{13}$.

Usually, such groups act to recruit corrupt persons from the sphere of public authorities, political or public organizations, decision-makers, specialists in the fields of interest, etc., such as:

- persons holding a public office;

- persons with decision-making functions or who take part in decision-making in public services, autonomous governments, commercial companies, national companies, etc.;

- persons who, according to the law, have control powers;

- specialists assisting public institutions and authorities, commercial companies, autonomous authorities, national companies;

- persons who carry out, control or provide specialized assistance, to the extent that they participate in making decisions regarding bank operations, foreign exchange, stock exchange, insurance, capital and bank accounts movement, domestic and international commercial transactions;

${ }^{13}$ Law no. 78/2000 for the prevention, discovery and sanctioning of corruption facts, published in the Official Gazette no. $219 / 18.05 .2000$, amended by the Emergency Ordinance no. 83 / 29.08.2000, Emergency Ordinance no. 43 / 04.04.2002 and Law no. 161 / 19.04.2003. 
- persons holding leadership positions in political parties, trade unions, non-profit associations, foundations, employers' organizations;

- other natural persons than those provided by law.

The mere casual collaboration with certain state officials - even if it is carried out by illegal means, such as, for example, by bribery - is not likely to include those who have competed in the commission of illicit acts.

Even if any of these categories may be of short-term interest in being included in an interest group, as a rule, the effective attraction is limited to persons whose utility is representative for the development and protection of the group's actions. Mainly, the persons performing representative functions in parliament, local councils and mayors, justice, prosecutor's office, police, ministries and other central economic institutions, in the field of privatization and the banking system, in the fiscal, financial and customs bodies, including those of control, are targeted, as well as in other organs of the state administration.

If the persons exercising such functions are not accessible to the group, then the whole group is mobilized to promote faithful or at least, to a significant extent, suitable, to be attracted first to the circle of relations and then gradually included in group.

Illegally obtained profits reach different destinations, such as recycling for washing, the creation of funds for participating in privatizations, given the low or inefficient concern of the authorities empowered to establish the origin of financial resources.

Organized crime becomes a threat, when:

- penetrates the main governing bodies of the state and extends its influence on the political life, on the economic sector, especially the financial-banking, commercial, industrial sector, but not least on the media, which it tries to control and use in formation of distorted images in connection with their illicit activities;

- the degree of professionalization of criminal media and structures is consolidated, and individuals with such concerns occupy official positions in the field of trade, justice, administration, communications, logistics, financial-banking etc.;

- the fusion with the political world is carried out, important funds resulting from corruption and mafia-type businesses (drug trafficking, high-smuggling acts, tax evasion, blackmail, collection of the protection tax) being injected into organizations and political and administrative structures so that they can be keep in power and be able to guarantee the groups of criminals the success and the multitude of dirty businesses that they initiate;

- the direct dispute between the criminal groups for acquiring or maintaining the supremacy in certain areas such as: drug trafficking, weapons, trafficking of live meat, smuggling of alcohol, cigarettes, works of art as well as the dispute for areas of influence is intensified;

- the forms and procedures used to wash dirty money multiply.

The case law reveals that the activity of interest groups (including those of pressure and lobby) is insufficiently regulated in Romanian law, the only references being made in the new Criminal Code regarding organized criminal groups. 


\section{Bibliography}

[1] Law no. 78/2000 on the prevention, discovery and sanctioning of corruption facts, published in the Official Gazette no. 219 / 18.05.2000, amended by the Emergency Ordinance no. 83 / 29.08.2000.

[2] Emergency Ordinance no. 43/04.04.2002.

[3] Law no. 161/19.04.2003.

[4] The Penal Code was adopted in 2009 (Law 286/2009) and entered into force on February 1, 2014. It contains 446 articles and is divided into two parts: General Part Articles (1-187) and Special Part Articles (188-446).

[5] DEX, "Encyclopaedic universe"Publishing House, Bucharest, 1996.

[6] Dictionary of Sociology, “Encyclopaedic universe” Publishing House, Bucharest, 2003.

[7] Sergiu Tămaş, Political Dictionary. Institutions of democracy and civic culture, „AcademieiRomâne ”Publishing House, Bucharest, 1993.

[8] Dictionary of Politics, "Encyclopaedic universe” Publishing House, Bucharest, 2001.

[9] ABRAHAM Pavel,Corruption: causes, mechanisms, effects, solutions, Bucharest, Detectiv, 2005.

[10] ANGIU Ilie,Risks and Threats to the Security of Romania.In: Proceedings: International Scientific Conference: Strategies XXI: The Complex and Dynamic Nature of the Security Environment, November 27-28, 2018.Bucharest, „Carol I” National Defence University Publishing House, 2018.

[11] BOBIAN Elisabeta,Criminal law: special part: course notes.Sibiu, Publishing House of the Academy of Land Forces "NicolaeBălcescu", 2015.

[12] CARAIANIGheorghe,Offshore companies and economic terrorism. Bucharest, Military Publishing House, 2017.

[13] HEDEŞIU Emil; TOMA, Gheorghe,Counteracting cross-border organized crime. Bucharest, Publishing House of the National Defence University, 2005. 